\title{
LA IDENTIDAD CONSTITUCIONAL MEXICANA: LÍMITE INFRANQUEABLE PARA EL EJERCICIO DEL PODER
}

\author{
The Mexican constitutional identity: Unbridgeable \\ limit for the exercise of power
}

\author{
ALEJANDRA FLORES MARTÍNEZ ${ }^{1}$ \\ Universidad Autónoma del Estado de México \\ licale_23@hotmail.com
}

Cómo citar/Citation

Flores Martínez, A. (2017).

La identidad constitucional mexicana: límite infranqueable para el ejercicio del poder.

Anuario Iberoamericano de Justicia Constitucional, 21, 37-57.

doi: https://doi.org/10.18042/cepc/aijc.21.02

\section{Resumen}

En este trabajo se cuestiona sobre si la identidad constitucional, más allá de lo explicitado por el lenguaje en el texto constitucional, se traduce en los valores ideológicos abrigados por el pueblo mexicano a través de un pacto federal y al entendimiento de lo fundamental en lo constitucional. A través de este estudio se concluye que la defensa de la identidad constitucional es el límite infranqueable ad intra y ad

1 Profesora e investigadora de tiempo completo en la Facultad de Derecho de la Universidad Autónoma del Estado de México, integrante del Cuerpo Académico Estudios Constitucionales de la misma facultad. Doctora en Derecho por la Universidad de Zaragoza, España. Exbecaria de la Fundación Carolina, Santander y la Universidad de Zaragoza. Integrante del Sistema Nacional de Investigadores (Nivel I). Fue coordinadora del Centro de Investigación en Ciencias Jurídicas, Justicia Penal y Seguridad Pública. Ha realizado estancias de investigación en la Oficina de Naciones Unidas, Ginebra, Suiza (2009) y en el Ibero-Amerikanisches Institut, Berlín, Alemania (2017). 
extra. Ad intra para los poderes constituidos y los ciudadanos; ad extra, para los órganos internacionales, el poder económico y de mercado. En este sentido, mientras no se defienda la identidad constitucional estaremos alimentando un constitucionalismo relativo.

\section{Palabras clave}

Identidad constitucional; constitucionalismo relativo.

\section{Abstract}

In this paper, it is questioned whether the constitutional identity, beyond what is explicitly expressed by the language in the Constitution, translates into the ideological values sheltered by the Mexican people through a federal pact and the understanding of the fundamentals in the constitutional field. Through this study we conclude that the defense of the constitutional identity is the ad intra and ad extra absolute limit. Ad intra, for the constituted powers and citizens; ad extra, for international organizations, the economic power and the market. In this sense, as long as the constitutional identity is not defended, a relative constitutionalism will be fueled.

\section{Keywords}

Constitutional identity; relative constitutionalism. 


\section{SUMARIO}

I. INTRODUCCIÓN. II. LA MANIPULACIÓN CONSTITUCIONAL, LO ACONSTITUCIONAL Y ANTICONSTITUCIONAL EN LA REALIDAD LOCAL-GLOBAL. III. SIGNIFICADO DE LA IDENTIDAD CONSTITUCIONAL. IV. LA IDENTIDAD CONSTITUCIONAL MEXICANA. BIBLIOGRAFía.

\section{INTRODUCCIÓN}

En este artículo se discute sobre el significado de la identidad constitucional, desde el enfoque epistemológico de este trabajo la falta de una identidad constitucional se traduce en un caos observado en fraudes, manipulaciones ${ }^{2}$ o «disfraces constitucionales» (Castillo y Castellano, 2009: 13-38) ${ }^{3}$. Además el fenómeno denominado "globalizador" parece impulsar una pérdida de la realidad constitucional, pues mientras hasta hace no todavía mucho tiempo el problema de la validez y la eficacia de los preceptos constitucionales se podía presentar como expresión del fenómeno de una normativa que se enfrentaba a una realidad poderosa, rebelde y resistente a dejarse dominar por el derecho,

2 Un ejemplo es la Sentencia 22/2013 que resolvió la Suprema Corte de Justicia de la Nación sobre la acción de inconstitucionalidad interpuesta por la Comisión Nacional de Derechos Humanos en contra del art. 132 del Código de Procedimientos Penales para el Estado de Hidalgo que regulaba el arraigo. En esta sentencia el argumento central fue que el arraigo es constitucional porque en la reforma a los arts. 16, 17, $18,19,20,21$ y 22; 73, fracciones XXI y XXIII; art. 115, fracción VII y la fracción XIII, del apdo. B, del numeral 123, todos de la Constitución Política de los Estados Unidos Mexicanos, publicada el 18 de junio de 2008, fue trascedente para el sistema de procuración e impartición de justicia en materia penal, establece un nuevo modelo de justicia penal para pasar del llamado sistema mixto al acusatorio u oral. Además, introduce la figura del arraigo,. es decir, para la Corte mexicana lo constitucional es lo expresado en el texto, independiente a si está o no conforme a los principios y valores constitucionales que forman parte de la identidad constitucional.

3 Castillo Sánchez y Castellano Morales aluden a que la figura del disfraz constitucional es la forma en la cual, en la historia colombiana, se ha mantenido una institucionalidad relativamente estable aunque no haya logrado consolidarse un estado constitucional, sino en las puras formalidades. 
lo que sucede ahora, como consecuencia irremediable de los procesos de la mundialización económica y de la reducción de los espacios políticos, es que esa realidad, objeto de regulación, se sitúa en otros ámbitos que la tradición normativa del derecho constitucional desconoce o intencionadamente ignora. Llevando el razonamiento hasta sus últimas consecuencias Pedro de Vega (1998: 31) sostiene que el derecho constitucional comienza a quedarse sin realidad constitucional.

Bajo este contexto, se cree preciso reflexionar sobre el significado de la identidad constitucional y avizorar las consecuencias prácticas, ante la ausencia de lo constitucional, en el ejercicio de las funciones de los tres ámbitos de gobierno y otras expresiones de poder. Por tanto, las cuestiones que se plantean en esta investigación son: ¿qué elementos identifican a una Constitución? ¿Tales elementos pueden trastocarse sin dañar el neumeno constitucional? ¿Existen elementos que distingan a una Constitución de otra u otras? ¿Cómo incluir otros fenómenos constitucionales? Y por último, se indaga sobre si la identidad constitucional es un límite para los poderes constituidos y para otros poderes, sean incluso supraestatales.

Esta investigación inicia con un diagnóstico actual de los fenómenos denominados: manipulación constitucional, lo aconstitucional y anticonstitucional desarrollados en la realidad local-global; que tienen como ingrediente principal el vaciamiento del contenido constitucional y democrático impulsado por reformas constitucionales. Después se analiza el significado de la identidad constitucional desde las teorías constitucionales actuales para finalmente adentrarnos en escudriñar sobre la identidad constitucional en México.

\section{LA MANIPULACIÓN CONSTITUCIONAL, LO ACONSTITUCIONAL Y ANTICONSTITUCIONAL EN LA REALIDAD LOCAL-GLOBAL}

En el escenario actual existen poderes que niegan, manipulan o actúan contra lo constitucional. En términos concretos vivimos una etapa de destrucción de la Constitución en manos del poder revisor. Jellinek (1991: 76) avizoraba que una oligarquía partidista sustituye, en estos Estados, a la democracia, tratando desconsideradamente a quien se cruza en su camino. La legislación parlamentaria es mala, partidista y deficiente, incoherente, deteriora las buenas ideas legislativas debido a malas formulaciones y añadidos inadecuados, que dependen de miles de incidencias de naturaleza personal.

De ahí que la manipulación constitucional sea definida como la utilización de la Constitución con un interés particular. Pedro Sagüés (2004: 5) refiere que la manipulación constitucional se detecta en tres factores esenciales: 
1) el «uso» o utilización de la constitución, lo que implica reducirla a la condición de objeto o herramienta manejada por el manipulador. Éste, en vez de servir a la Constitución, se sirve de ella.

2) con ardid, vale decir, merced una maniobra, artificio o engaño, treta generadora de una «interpretación manipulativa» de la ley suprema, que procura hacer pasar gato por liebre constitucional.

El mismo autor comenta que existe la manipulación partidista, en esta variable la Constitución es usada para legitimar la acción de partidos políticos concretos. Sus cláusulas pueden ser torcidas tanto para fundar determinados proyectos, como para justificar hechos consumados o comportamientos en trámite (Sagüés, 2004: 15). Aunque, la teoría constitucional denuncia que un acuerdo político no puede estar por encima de los principios que identifican a una Constitución, las circunstancias indican que existe una ausencia de esta identidad constitucional que alimenta una especie de anarquismo que se refleja en ausencia de gobierno, ausencia de cumplimiento de normas, ausencia de orden y ausencia de confianza ciudadana.

Asimismo, la vicisitud de poderes económicos y los espacios supraestatales que generan una especie de enfrentamiento entre la mundialización económica y el Estado; en otras palabras, entre la lógica del cálculo y la ganancia y la lógica de las valoraciones políticas constitucionales de la acción estatal (Jáuregui Gurutz, 1998: 45 y ss.). Este enfrentamiento se hace patente con el enorme aumento de la desigualdad que ha acompañado la difusión del liberalismo de mercado. Esto es importante porque, además de sus implicaciones morales, el aumento de la desigualdad puede menoscabar gravemente el bienestar social, poner en peligro la estabilidad, el progreso económico y socavar la cohesión política (Conferencia de las Naciones Unidas, 2014). Una de las situaciones más peligrosas es el retroceso en la protección de los derechos fundamentales; tarea principal para el Estado Constitucional. Esas zonas supraestatales son espacios aconstitucionales porque desbordan el ámbito propio de las Constituciones, pero además funcionan al margen y aún en contra de lo que el constitucionalismo ha significado y puede significar (De Cabo Martín, 2014: 18). La aconstitucionalidad se entiende como todo aquello que no es reconocido por la esencia de lo constitucional, mientras que la anticonstitucionalidad es atentar contra esta esencia.

Para algunos constitucionalistas estos poderes impulsan procesos deconstituyentes, es decir, procesos de vaciamiento del contenido democrático y garantista de las constituciones vigentes por vías diversas:

a) inaplicación lisa y llana;

b) aplicación restrictiva: 
c) mutaciones tácitas;

d) reformas explícitas;

e) subordinación de normas de contenido inconstitucional provenientes de ordenamientos supranacionales (Pisarello, 2014: 18).

De una revisión general de algunos nuevos textos o reformas constitucionales de países iberoamericanos, avizoramos este vaciamiento del contenido constitucional y democrático ${ }^{4}$. Es decir, las reformas constitucionales se convierten en mecanismos mediante los cuales se positivizan contenidos que atentan contra los principios que identifican a una Constitución; no solo son inconstitucionales sino son anticonstitucionales. A este fenómeno la doctrina italiana la denomina costituzione abdicataria, esto es, Constituciones que ceden o mutan su esencia para cobijar los deseos de poderes políticos o económicos (Guanni Ferrara, 2012).

En México las últimas reformas constitucionales provienen de un pacto político, que según expertos representan la fuerza política del país; sin embargo, bajo una perspectiva crítica tales cambios, principalmente en materia económica, son resultado de atender las recomendaciones de organismos internacionales. Las reformas fueron en materias muy importantes, entre ellas están:

1. La reforma energética que permite la participación de empresas privadas para la explotación y exploración de hidrocarburos (Secretaría de Relaciones Exteriores, 2013) ${ }^{5}$.

4 En Venezuela una Asamblea Constituyente aprobó en 1999 un proyecto de Nueva Constitución que fue ratificada por referéndum y que permitió la reelección presidencial inmediata por un período. El 15 de febrero del año 2009 mediante referéndum se aprobó la reelección presidencial inmediata e ilimitada.

En España se modificó el art. 135 constitucional en lo relativo a la estabilidad presupuestaria y déficit estructural conforme a los parámetros fijados por la Unión Europea (27 de septiembre del año 2011).

En Paraguay en marzo de este año se aprobó la reelección presidencial a pesar de que la Constitución no lo permitía y las voces de académicos constitucionalistas subrayaron que la no reelección era una decisión política fundamental.

5 Hay discrepancias entre la propuesta y las ventajas que inicialmente anunció el presidente Peña Nieto y la situación real: en un comunicado el presidente Enrique Peña Nieto sostuvo que a través de esta reforma se busca modernizar la industria petrolera nacional, confirmando la propiedad de la nación sobre los hidrocarburos. Los objetivos de esta reforma energética son: mejorar la economía de las familias; bajarán los costos de los recibos de la luz y el gas. Al tener gas más barato se podrán producir 
2. La reforma político-electoral que centraliza funciones para la organización de elecciones locales por un Instituto Nacional Electoral, en otros términos, dicho instituto tiene facultades exclusivas en las elecciones locales en cuanto a la capacitación electoral, la ubicación de casillas y la designación de los funcionarios de sus mesas directivas, la geografía electoral, el diseño y determinación de los distritos electorales, división del territorio en secciones electorales, el padrón y la lista de electores, la fiscalización de los ingresos y egresos de los partidos políticos y candidatos. Tales atribuciones nulifican la participación de los Institutos Electorales de cada entidad federativa en el proceso para elegir autoridades locales. Además, la modificación constitucional admite la reelección consecutiva en tres ámbitos: legislativa federal, legislativa local y municipal (México. Gobierno de la República, 2013).

3. La reforma hacendaria que cambia el régimen de pensiones siguiendo la sugerencia de la Organización para la Cooperación y Desarrollo Económico (OCDE). Estudios indican que México en los últimos veinte años ha convertido todas las recomendaciones de la OCDE en políticas públicas e incluso en reformas constitucionales. El actual presidente de la República firmó un acuerdo de colaboración estratégica con la OCDE para crear el Plan Nacional de Desarrollo; es decir, no atendió las necesidades económicas internas, no acudió a grupos nacionales para fijar las prioridades y el proyecto de gobierno (Vicher Diana, 2014: 129 y 130) ${ }^{6}$.

Los sucesos descritos llevan consigo una suplantación de la democracia e implican retos que el constitucionalismo actual debe abatir. Ya que los operados económicos parece que funcionan fuera de la Constitución e incluso como lo sostiene de Cabo Martín (2014: 74):

[...] se denuncia que el relato que se ha hecho sobre la crisis económica y su tratamiento ha sido al margen de la Constitución, haciendo de la crisis un espacio sin vigencia constitucional, lo que se denuncia no es simplemente una infracción

fertilizantes de mejor precio, lo que resultará en alimentos más baratos. Sin embargo, a principios del año 2016 se anunció un incremento en los costos de luz eléctrica.

6 A continuación se presenta un botón de muestra: en su documento de la OCDE sugiere «fortalecer los compromisos de México derivados de acuerdos de inversión extranjera. Entre ellos los Códigos de la OCDE para la Liberalización de Movimientos de Capital y Operaciones Corrientes Invisibles, se incluyen también los servicios bancarios». Mientras que en el PND se reafirma el compromiso del país con el libre comercio y la movilidad de capitales. OCDE dice: «Reducir las necesidades de endeudamiento del sector público». PND propone: "Diseñar una política hacendaria integral que permita al gobierno mantener un nivel adecuado de gasto ante diversos escenarios macroeconómicos y que garantice la viabilidad de las finanzas públicas». 
formal sino que esta «ausencia de Constitución» lo que ha producido es una marginalización y una ausencia de los ciudadanos, una ausencia de constitucionalización de la realidad social con todo su contenido garantista.

En América Latina el proceso de integración económica está marcado por divisiones internas, la existencia de más de ochenta acuerdos sectoriales, la proliferación de más de cuarenta protocolos, tratados y declaraciones, el fracaso de esquemas de integración a nivel Caribe, Centro América, Sudamérica, América del Norte y Panamericanos (Pamplillo, 2014: 91 y ss.). Aunado a los problemas comunes: la necesidad de consolidar la democracia, fortalecer el Estado constitucional, garantizar el respeto a los derechos humanos, promover una economía abierta y equilibrada, que además contribuya a reducir la desigualdad y la pobreza en la región.

Ante este escenario la doctrina constitucional en su mayoría apuesta por un ius commune interamericano en materia de derechos humanos (Fix Zamudio, 2002: 165; Hitters, 2009: 109-128; Sagüés, 2010: 449), la nacionalización del derecho internacional de los derechos humanos (García Sayan, 2005: 324) o un ius commune americanus (Pamplillo, 2014: 91). En México son mayoría los constitucionalistas que apuestan por el denominado ius commune americanus; no obstante, resulta epistemológicamente incorrecto querer abrigar modelos globales sin contar con modelos que aglutinen la esencia constitucional desde el contexto de las entidades federativas y las condiciones de vida de los ciudadanos mexicanos.

Todo indica que nos encontramos en una encrucijada consistente en saber cómo y qué requiere el constitucionalismo de hoy para enfrentar los avatares económicos supraestatales e incardinar lo constitucional desde una praxis local. Una parte de la doctrina apuesta por reconocer el fracaso del constitucionalismo anterior y atreverse a pensar algo diferente, mientras que teóricos, principalmente estadounidenses, defienden la idea de reforzar la identidad constitucional. Desde la óptica teórica de este trabajo se sugiere no negar los principios fundantes del Estado constitucional, todo lo contrario, es necesario partir de ellos para ensamblar nuevos contenidos identitarios que refuercen los vínculos y los límites que imponen las Constituciones a cualquier destello o relámpago de poder. Aquellos que declaran el fracaso del constitucionalismo caen en la conducta de quienes están por encima de los principios constitucionales; esto es, niegan lo constitucional.

\section{SIGNIFICADO DE LA IDENTIDAD CONSTITUCIONAL}

El delinear la identidad constitucional es un reto para la teoría constitucional debido a la existencia de fuerzas tensionantes; por un lado, las 
relaciones entre los diversos órganos del Estado; por el otro, la confrontación constitucional con el orden social desde las perspectivas pasada, presente y futura; por último, los poderes económicos, políticos y financieros que parece se extraen de los límites constitucionales. Dichas tensiones se manifiestan en las aspiraciones sociales contradictorias que convergen en un Estado y que permiten asegurar que la identidad constitucional es una construcción diaria. Sin embargo, también es importante detectar los elementos determinantes o fundamentales de una Constitución con ánimos de no alterar su noúmeno o esencia, así como identificar los rasgos que distinguen a una Constitución de otra u otras. Desde la visión teórica de este estudio, el no definir un contenido mínimo o identificador constitucional propicia un "constitucionalismo relativo" o "constitucionalismo de situación"; a saber, como lo sostiene Pedro de Vega (1998: 30), la confrontación entre norma y realidad adquiere proporciones distintas, y ofrece significados diversos por la influencia unilateral de los poderes políticos y económicos.

De entrada se considera que la identidad constitucional sugiere contenidos metaconstitucionales por esos principios y valores preconstitucionales que definieron la esencia y significado de las Constituciones. Para Smend (1985) la singularización de las normas constitucionales son normas de cultura, que recaban fundamentaciones extranormativas, lo que conlleva que sus elaboraciones puedan ser dinámicas y variables. En este sentido, Klug Heinz (2011: 4) refiere que la identidad constitucional surge de una manera dialógica y representa una mezcla de aspiraciones políticas y compromisos que son expresión del pasado de una nación, así como la determinación de aquellos escollos que la sociedad busca de alguna forma trascender de ese pasado.

Por su parte, Bruce Ackerman (2015:199) asegura que la fundación constitucional, refiriéndose a la historia constitucional estadounidense, es el comienzo de un diálogo entre el pasado y el presente que nos servirá de técnica central para el descubrimiento constitucional o la naturaleza constitucional. Para él la identidad constitucional se halla en la dialéctica de los valores defendidos en el pacto fundacional y los valores que han ido abrigando los ciudadanos estadounidenses; un espejo dialéctico mediante el cual los estadounidenses vislumbran sus identidades constitucionales. Dicha dialéctica la plantea a través de la siguiente interrogante: ¿podemos reconocer las formas históricas y morales en las que nosotros somos diferentes de ellos y; sin embargo, encontrar puntos de contacto dialéctico que iluminen sinceramente el vínculo sin solución de continuidad que nos une a nuestros orígenes?

Por tanto, la Constitución es mejor entendida como una tradición histórica de teoría y práctica constitucional, un lenguaje político que ha ido evolucionando, y que permite a los ciudadanos, de diferentes siglos, ir construyendo una identidad nacional. De manera que la Constitución es un acto 
profundamente significativo de autodefinición colectiva; su continua readaptación desempeña un papel fundamental en la construcción en curso de la identidad nacional (Ackerman, 2015: 57 y ss.).

Luego entonces, desde la visión de Ackerman, la identidad constitucional se construye a través de un camino dialógico entre los valores del pasado con los principios del presente. Con ello se quiere decir, que todas las Constituciones cuentan con un momento histórico fundacional que manifestó los principios; o sea, el «sentir jurídico» de los ciudadanos sobre lo que debía ser el derecho y la intención de lograr una integración política. Por consiguiente, se sostiene que parte de la identidad constitucional está compuesta por principios metaconstitucionales que posteriormente fueron positivizados en el texto. Además, esta construcción dialéctica confirma la estrecha unión entre los principios fundacionales y el contexto actual, tal como lo asevera Jacobsohn: the future of constitutional identity is inscribed in its past (Gary Jeffrey, 2010: 349).

Desde la postura de Smend (1985) la Constitución es una ordenación jurídica de la integración política de los ciudadanos en el Estado y, por ello, también el fruto de la eficacia integradora de sus normas, muy especialmente de sus valores y derechos fundamentales. Para él, siguiendo a Riezler, existen tres elementos básicos que conforman el sentimiento jurídico: el primero, sentir sobre lo que es derecho, o sea, la capacidad que capta, intuitivamente, y aplica justamente el derecho vigente; a esta capacidad la denomina tacto jurídico o sensu jurídico; en segundo lugar, el sentir sobre lo que debe ser el derecho existente en cuanto inclinación al ideal jurídico; finalmente, la actitud respecto al derecho existente, es decir, el sentimiento de respeto del ordenamiento jurídico vigente (Lucas Verdú, 1985; López, 1993: 284).

A partir de esta vertiente ideológica la Constitución no crea los principios, solo les otorga una existencia jurídica-normativa ya que los principios y valores descansan en el sentimiento jurídico que los inspira; provienen de una conciencia jurídica colectiva. Pedro de Vega (2004: 285 y ss.) también defiende una visión de la Constitución como la expresión jurídica de un sistema de valores, a los que se pretende dar un contenido histórico y político; la Constitución entendida como una realidad normativa y no como una mera configuración nominal y semántica. Por ende, cuando las Constituciones, no actualizan un sistema de valores, se convierten en meros instrumentos de falsificación de la realidad política.

Para Lucas Verdú (2009: 118 y ss.) la dimensión axiológica de las prescripciones en la Constitución se encuentra en:

La razón que se realiza en un pueblo libre y en sus instituciones es la conciencia que vuelve a unirse íntimamente con su propia sustancia ética, convirtiéndose en Espíritu. 
El Espíritu es el individuo que constituye un mundo como el que se lleva a cabo en la vida de un pueblo libre. El Espíritu se proyecta en los valores. Es un Espíritu valorativo y en cuanto tal está latente, vivo y con propósito firme de hacerse efectivo en la convivencia política universal. Nuestra Constitución expresa esa proyección cuando recoge en su articulado el conjunto de valores.

Por esta razón, la identidad constitucional, en una primera estadía, está compuesta por los principios y los valores fundacionales; los contenidos que determinaron la existencia de las Constituciones que buscaban una forma de sociedad y Estado. La correlación entre la conciencia-sentir del sujeto y los principios fundantes constitucionales es clave para tejer una identidad constitucional; una relación entre el sistema político, jurídico y económico que se busca instaurar y los tipos antropológicos (Noguera Fernández, 2014: 209). Debido a la ruptura entre estos elementos, en Latinoamérica, se instauran regímenes tiránicos; sin embargo, la alianza entre ellos, también, propició revoluciones y nuevas Constituciones. De esta manera, la construcción y desarrollo de la identidad constitucional depende de factores contextuales y relacionales; por tanto, es importante no defender una identidad general de la Constitución, sino el acomodamiento de las diversas identidades individuales; se sugiere renunciar a generar una particular identidad constitucional. Rosenfeld lo refiere en los siguientes términos: Inasmuch as constitutionalism implies pluralism and heterogeneity, constitutional identity cannot be reduced to a mere relationship of similarity (Citado en Tushnet: 2010: 673).

De manera que es relevante recalcar que la identidad constitucional no se agota en los principios fundantes. El acto fundacional es un sistema de los «primeros principios» que definen la esencia de lo constitucional; son los compromisos obligados para los ciudadanos en el pasado y en el futuro; por ende, la Constitución es incompleta; su defensa y reconstrucción dependerá de las generaciones futuras: it will always depend on later generations to carry it forward, to embrace and preserve its constitutional identity and political creed (Beaumont, 2014: 219 y ss.).

De ahí, que en una segunda estadía dialéctica, la identidad constitucional esté forjada por los principios o valores que se reconstruyen en el trayecto histórico-sociológico de un país. Reconstruir significa allegar o evocar las ideas constitucionales para completar su conocimiento (Diccionario de la Real, 2016); se entabla una dialéctica entre los principios fundantes y los presentes para poseer una identidad constitucional. En concreto, como lo refiere Sunstein (2001: 50), por propia naturaleza, la Constitución representa acuerdos teóricos incompletos incompletely theorized agreements y por lo mismo no se puede pretender que la Constitución zanje las controversias sociales fundamentales. Ya que si se permanece en la inmovilidad constitucional se cae 
en el desafortunado terreno del conflicto social por la falta de facticidad en la norma.

En los mismos términos se expresa Edmund Burke (1996: 58), quien alude que «un Estado sin medios de efectuar algún cambio carece de medios propios de conservación. Sin tales medios puede incluso correr el riesgo de perder aquella parte de la Constitución que desea conservar más religiosamente». Así la Constitución juega un papel protagónico para incluir diversas identidades culturales-societarias con el propósito de lograr una convivencia pacífica. Empero, no se deben defender prácticas como las manipulaciones constitucionales o anticonstitucionales; incluir artículos expresos en los propios textos constitucionales que atenten contra su espíritu. Ya que las reconstrucciones deben partir siempre de los elementos fundantes.

En consecuencia, resulta relevante articular un contenido mínimo que identifique lo fundamental en lo constitucional. Sunstein (2001: 10) opta por identificar el piso institucional mínimo que constituye un precompromiso; un sentido mínimo constitucional. Mientras que Klug (2011: 4) afirma que la construcción de lo constitucional a través de un camino dialógico requiere la reconsideración del modelo jurídico-céntrico de la teoría constitucional contemporánea. Es decir, aquellas corrientes teóricas que explican lo constitucional desde aspectos megalómanos positivistas.

Poblete lo explica de la siguiente manera: «Este sustrato identificador, que existe más allá de la coincidencia textual, hace posible que, a partir de dos meta-constituciones similares, dos normas distintas signifiquen prácticamente lo mismo» (Nuñez, 2008). Por consiguiente, para trazar el núcleo de la identidad constitucional se debe partir de los principios y valores constitucionales fundacionales que a su vez son reconstruidos o trasmutados por las nuevas generaciones y que en conjunto forman una especie de información genética constitucional.

El núcleo constitucional fundacional está integrado por principios metaconstitucionales que fueron positivizados y que constantemente se actualizan por la lectura de una realidad cambiante. Así, desde las etapas descritas se ampara una lectura cívica de lo constitucional. Elizabeth Beaumont (2014: 28) expone que el acto fundacional de las Constituciones abraza cuatro procesos: the act of constitution, which includes the configuration of citizens and culture to sustain a commitment to constitutional norms, principles, and values. A través de un lente cívico y cultural los ciudadanos somos responsables de garantizar las promesas constitucionales porque la Constitución representa quiénes fuimos, quiénes somos y quiénes aspiramos a ser.

Este proceso para la construcción de la identidad constitucional se explica, desde la teoría de integración de Smend, para él la integración no es una definición, sino una concepción de la esencia de la constitución del 
Estado en cuanto comunidad política y de los procesos en que esa comunidad se realiza. Estos procesos están representados por tres tipos de integración: personal, funcional y objetiva. Entonces resulta, que es precisamente al agolparse los sentimientos jurídicos de una colectividad inspirados en un espiritu cuando se producen las integraciones: personal, funcional y objetiva para edificar la identidad constitucional. Fritz K. Ringer alude que la palabra alemana Geist no solo significa «mente» sino también «Espíritu» o «alma». En las obras de algunos idealistas, Geist representa el pensamiento colectivo de la humanidad y, a veces, incluso, una conciencia trascendental que garantiza la correspondencia de apariencia y realidad (Fritz, 1985: 104).

Por ello, para ser una realidad histórica, la identidad constitucional demanda una integración personal, que se refiere a los dirigentes políticos que a través de sus funciones objetivas han de lograr cohesionar al grupo político que les sostiene. Una integración funcional o procesal, que consiste en que las elecciones y votaciones promuevan y desarrollen la sustancia espiritual de la comunidad; por tanto, son procesos de conformación de la voluntad comunitaria, pretendiendo actualizar o renovar la comunidad política como comunidad de valores. Y finalmente, una integración material u objetiva, esta tercera forma de integración se refiere a un conjunto de valores que son vividos como comunes por la comunidad, se trata de una sociabilidad de las vivencias sustantivas (Brage, 2005: XXII y XXIII).

De modo que la unión de la identidad constitucional con la integración del individuo es insoslayable para la observancia y defensa de la Constitución a través del comportamiento de los ciudadanos; dicho de otro modo, la conciencia constitucional del ciudadano es un mecanismo de control constitucional. Avanzando en el razonamiento, se debe plantear lo siguiente: qué nuevos principios pueden tomarse como parte de la conciencia constitucional actual y del espíritu de la Constitución; a lo que se puede contestar que aquellos que logren contar con los tres niveles de integración: personal, procesal y objetiva. Además, es necesario puntualizar que al ser la Constitución una identidad entre los valores pasados y presentes las reconsideraciones constitucionales deben ser en el sentido de fortalecer o ampliar esos principios fundantes o incluso interpretarlos bajo nuevas realidades, pero nunca en transgredirlos o suplantarlos dado que esa tarea le corresponde al poder constituyente originario.

Se cree necesario reforzar este trayecto dialéctico para la construcción de la identidad constitucional; ya que, el no contar con el piso mínimo identificador propicia suplantaciones del poder constituyente en manos del poder reformador, el intérprete constitucional o, incluso, por poderes económicos. Definitivamente, es necesario que se identifique ese piso mínimo constitucional 
que representa el sentir de los ciudadanos del pasado en su reflejo con el sentir de las generaciones presentes y futuras.

\section{LA IDENTIDAD CONSTITUCIONAL MEXICANA}

En este año que celebramos el centenario de la Constitución mexicana, merece la pena evaluar qué significado tiene su identidad. Nuestra norma fundamental cuenta con 699 reformas, los últimos dos presidentes impulsaron más de cien reformas cada uno y así aumentaron más de cien mil palabras al texto (Fix Fierro y Valadés, 2017: 2 y 3). Sin embargo, en contraste con el espíritu de la reforma, que es precisamente el ajustar la norma suprema a las nuevas realidades, la encuesta sobre cultura constitucional, desarrollada por la Universidad Nacional Autónoma de México (2011), reportó que el 56,5 \% de las personas encuestadas ${ }^{7}$ considera que la Constitución no es adecuada a las necesidades del país y el 65,1\% acepta que conoce poco a la Constitución. De tales resultados se hace notar la contradictoria postura del ciudadano, ya que si conoce poco a la Constitución cómo infiere que no se ajusta a las necesidades del país.

Aunado a ello, Fix Fierro y Valadés (2017) detectaron algunos errores de falta de técnica y sistemática en los diversos artículos constitucionales, entre ellos destacan:

- presencia de disposiciones duplicadas;

- uso variable e inconsistencia de la terminología;

- disparidad en el alcance y profundidad de la regulación;

- desorden y falta de sistema en la materia regulada en los artículos constitucionales;

- deficiente ubicación de las disposiciones constitucionales;

- errores en la actualización del texto.

7 Con la finalidad de replicar la Encuesta Nacional de la Constitución, se diseñó una muestra a nivel nacional. Para recopilar la información, se propuso un muestreo con un esquema polietápico, estratificado, por conglomerados, como se detalla a continuación:

Con fines de comparabilidad, se dividió al país en las cuatro regiones que se utilizaron durante el primer estudio: Región I. Baja California, Baja California Sur, Coahuila, Chihuahua, Durango, Nuevo León, Sinaloa, Sonora, y Tamaulipas. Región II. Aguascalientes, Colima, Guanajuato, Jalisco, Michoacán, Nayarit, Querétaro, San Luis Potosí, y Zacatecas. Región III. Distrito Federal, Hidalgo, México, Morelos, Puebla y Tlaxcala. Región IV. Campeche, Chiapas, Guerrero, Oaxaca, Quintana Roo, Tabasco, Veracruz, y Yucatán. 
La Constitución está funcionando norma reglamentaria.

La propuesta de estos especialistas fue crear una ley de desarrollo constitucional como una especie de depuración normativa. No obstante, desde la visión epistemológica de este estudio, más allá de la falta de técnica y sistemática, se considera que el fenómeno responde a una nula identidad constitucional que no se subsanará con una ley de desarrollo constitucional o incluso con una nueva Constitución. Como se viene sosteniendo es necesario discernir los valores fundantes y presentes, identificar los rasgos fungibles y los elementos «determinantes» (en la terminología de Constantinesco) de nuestro orden jurídico constitucional. Estos elementos determinantes «atribuyen a todo orden jurídico su individualidad específica» $y$, consecuencialmente, su identidad (1981: 318 y ss.). En resumidas palabras, es identificar quiénes fuimos, quiénes somos y quiénes deseamos ser.

Parafraseando a Ackerman (2015: 206 y 264) planteo lo siguiente: dado el papel que han jugado tanto la política constitucional como el derecho constitucional en la lucha de México por la limitación del poder y por el autoentendimiento; ¿acaso no tenemos la obligación con nosotros mismos de tomarnos este ámbito en serio? No porque contenga la última palabra respecto a lo que significa ser mexicano (ningún ámbito es lo bastante rico para ello), sino porque seguramente, sin las ideas preconstitucionales, faltaría una pieza importante del rompecabezas, y tendríamos que preguntarnos qué ha sido de su espíritu revolucionario. De ahí, que el interés de este artículo sea reflexionar sobre el significado de la identidad constitucional mexicana.

Siguiendo la teoría de Ackerman, para fijar la identidad constitucional a través de un espejo dialéctico entre los valores pasados y presentes, la identidad constitucional en México estaría compuesta, en un primer momento, por los principios fundantes abrigados por la Constitución de 1917. La Constitución de México arropó los principios metaconstitucionales inspirados por el sentir de un pueblo con conciencia jurídica sobre lo que deseaba fuera su Estado y con el anhelo de contar con un sistema económico y político justo. De esta forma, la convergencia entre los tipos antropológicos y el lenguaje político-constitucional de nuestra norma fueron propicios para exportar al mundo un constitucionalismo social.

Nuestra fundación constitucional arropó los principios del liberalismo como son: la soberanía popular (en el art. 39), la división de poderes (en el art. 49), los derechos individuales (en los arts. 1 al 24), el sistema representativo democrático (en el art. 40) y las garantías constitucionales (en el art. 105). Pero, el constituyente de 1917 se olvidó de los límites del derecho constitucional clásico, vigentes entonces en el mundo, para recoger los ideales revolucionarios del pueblo mexicano a través de un constitucionalismo llamado «Social». 
Los derechos sociales que reconoció nuestra Constitución brotaron del sentir de un pueblo lastimado por hechos injustos. Cabrera redactó tales injusticias de la siguiente forma:

El caciquismo o sea la presión despótica ejercida por las autoridades locales que están en contacto con las clases proletarias, y la cual se hace sentir por medio del contingente, de las prisiones arbitrarias, de la ley fuga, y de otras múltiples formas de hostilidad y de entorpecimiento a la libertad del trabajo.

La esclavitud o servidumbre feudal que se encuentra el peón jornalero.

La servidumbre personal y económica a que está sometido el obrero fabril.

La presión económica y la competencia ventajosa que la gran propiedad rural ejerce sobre la pequeña.

El acaparamiento comercial y financiero y la competencia ventajosa que ejercen los grandes negocios sobre los pequeños como consecuencia de la protección oficial y de la influencia política que sus directores pueden poner al servicio de aquéllos.

El predominio y la competencia ventajosa que ejercen en todo género de actividades los extranjeros sobre los nacionales (Meyer, 1992: 17).

Por consecuencia, la Constitución de 1917 encierra los valores y principios fundacionales que muestran la mezcla de aspiraciones políticas y compromisos que son expresión del pasado de nuestra nación, así como la determinación de aquellos obstáculos que la sociedad buscaba trascender de ese pasado. El poder constituyente quiso fundar un Estado social, justo y democrático donde se respetara la libertad de los mexicanos, que la Constitución fuera el control para el poder político y además se deseó preservar el federalismo y al municipio libre. El primer jefe del Ejército Constitucionalista, encargado del Poder Ejecutivo de la Unión, Venustiano Carranza, en la tarde del viernes primero de diciembre de 1916, en la sesión inaugural donde hizo entrega del proyecto de reforma de la Constitución, pronunció un discurso que definió la misión del poder constituyente; destacando lo siguiente:

Lo primero que debería hacer la Constitución política de un pueblo era garantizar, y no simplemente declarar, a la libertad humana, resguardo que no habría efectuado apropiadamente la ley suprema del «57», ni sus leyes secundarias...

El pacto federal también ha sido violado, ya que no se ha respetado la libertad y soberanía interior de los estados, siendo el poder central en que siempre ha impuesto su voluntad, ignorándose, por consiguiente, la forma republicana, representativa y popular adscrita constitucionalmente a las entidades federativas (Rabasa, 2016: 93).

El poder constituyente tuvo la misión de generar el acuerdo político que actualizara el sistema de valores; es decir, las aspiraciones sociales del pueblo mexicano que finalmente se reflejaron normativamente en la elaboración, 
debate y aprobación de los siguientes artículos: art. 3 sobre la libertad de enseñanza; arts. 5 y 123 sobre el trabajo y la previsión social; art. 27 en cuanto a la reforma agraria -aquí vale la pena anotar que se concedió la propiedad de los recursos naturales del subsuelo a la nación y se fijó la prohibición de los extranjeros para ser propietarios en una faja de $100 \mathrm{~km}$ de la frontera y $50 \mathrm{~km}$ de las playas-; arts. 25 y 28 relativos a la prohibición de los monopolios y la rectoría económica del Estado, y arts. 24 y 130 sobre la supremacía del Estado sobre la Iglesia.

En lo relativo a la supremacía del Estado sobre la Iglesia, la Comisión redactora hizo una contrapropuesta al proyecto de Carranza. Se dijo que no se trataba de proclamar la simple independencia del Estado, como lo hicieron las leyes de Reforma... sino establecer marcadamente la supremacía del Poder civil sobre los elementos religiosos (González, 1992: 347). Reyes Heroles (1967: VIII) definió tal supremacía como una doctrina mexicana forjada por largas luchas:

La solución mexicana al problema de las relaciones Estado-Iglesia, elaborada en el curso de un largo proceso histórico, con importantes perfiles ideológico-políticos, se basa fundamentalmente en la separación Estado-Iglesia; en la secularización de la sociedad para convertirla en una sociedad libre; en la consignación de la libertad espiritual fundamental del hombre, que es la de conciencia, y en la superación de la antítesis - tan cara a los europeos- de Iglesia propietaria o Iglesia asalariada del Estado. Junto a ello, la solución mexicana afirma la supremacía estatal y establece regulaciones en lo relativo a efectos sociales del culto religioso y a impedir — consejo deducido de nuestra experiencia histórica — la acción política del clero.

Por ende, parte de nuestra identidad constitucional está delineada por la supremacía del Estado frente a expresiones religiosas con el ánimo de contar con estabilidad duradera y una paz firme para todos los mexicanos independiente al credo religioso que se profese.

Otro de los valores que cobijó la Constitución fue el lema político de la Revolución mexicana «No reelección presidencial». Cabe mencionar, como lo indica Medina Pérez (2006: 5) que la no reelección absoluta del presidente de la República se propuso en el Proyecto de don Venustiano Carranza y su instauración constitucional fue pronunciada de manera favorable por la comisión correspondiente del congreso de Querétaro como «una conquista de la revolución que desde 1910 la escribió en sus banderas».

Por todo lo anotado hasta aquí, se vislumbra que desde el enfoque teórico de este estudio se defiende que para trazar nuestra identidad constitucional se requiere de elementos contextuales y antropológicos vividos antes y después de la instauración del pacto federal; esto es, ser conscientes del sentir jurídico de los ciudadanos del ayer y del hoy. Siguiendo a Sunstein (2001: 
10), en cuanto a identificar el piso institucional mínimo que constituye un precompromiso; un sentido mínimo constitucional, en México es crucial rescatar esos valores o principios fundacionales que nutren nuestra esencia constitucional. Luego entonces, solo así se podría entablar una dialéctica entre los valores y principios fundacionales con los principios o valores de las nuevas generaciones, forjando un diálogo intergeneracional. No hay que olvidar que la Constitución es una idea teórica incompleta.

Por tanto, solo identificando este piso mínimo constitucional es como podremos las nuevas generaciones dar respuesta a la interrogante hecha por Ackerman: ¿Podemos reconocer las formas históricas y morales en las que nosotros somos diferentes de nuestros ancestros y; sin embargo, encontrar puntos de contacto dialéctico que iluminen sinceramente el vínculo sin solución de continuidad que nos une a nuestros orígenes?

Las nuevas generaciones poseemos el derecho y la obligación de contestar si esos principios fundantes siguen siendo propicios para reconocernos moralmente en ellos; o no. Lo que no puede acontecer es que la ignorancia de los principios constitucionales nos arroje a la intrépida salida de buscar una nueva Constitución o seguir caminando sobre los lineamientos de un constitucionalismo relativo. También el identificar los elementos determinantes de la Constitución lleva implícita la labor de contribuir a su perfeccionamiento y seguir construyendo nuestra identidad. Por ende, cuestionarnos qué ideas teóricas constitucionales aportaremos para sortear los escollos actuales.

Para los escépticos de la importancia de defender la identidad constitucional, sustento que a partir de todo lo argumentado, a lo largo de estas líneas, la identidad constitucional reportó la posibilidad de instaurar patrones de comportamiento para fundar un Estado democrático; por consiguiente, todos los ciudadanos debemos autonombrarnos custodios de los principios constitucionales. De lo contrario, corremos el riesgo de convertir lo constitucional en mera ficción jurídica (Vega, 2004: 297). Estamos inmersos en la ausencia constitucional para la toma de decisiones y vivimos una indolencia hacia los principios constitucionales por parte de poderes públicos, poderes privados y el mismo ciudadano. Fenómenos que se podrán corregir si defendemos nuestra identidad constitucional y la imponemos como límite a cualquier destello o relámpago de poder.

\section{Bibliografía}

Ackerman, B. (2015). We the people way I. Fundamentos de la historia constitucional estadounidense. Ecuador: Instituto de Altos Estudios del Ecuador. 
Beaumont, E. (2014). The civic Constitution: Civic visions and struggles in the path toward Constitutional democracy. USA: Oxford University Press. Disponible en: https:// doi.org/10.1093/acprof:oso/9780199940066.001.0001.

Brage Camazano, J. (2005). Estudio preliminar. En R. Smend. Ensayos sobre la libertad de expresión, de ciencia y de cátedra como derecho fundamental y sobre el Tribunal Constitucional alemán (pp. XI-LX). México: Universidad Nacional Autónoma de México.

Burke, E. (1942). Textos políticos. México: Fondo de Cultura Económica.

Castillo-Sánchez, C. y Castellanos-Morales, E. (2009). El disfraz constitucional: el constitucionalismo relativo. Papel Político, 14 (1), 3-38.

Conferencia de las Naciones Unidas Sobre el Comercio y Desarrollo. (2014). Informe sobre el comercio y desarrollo. Nueva York y Ginebra: ONU.

Constantinesco, L. (1981). Tratado de Derecho comparado. Madrid: Tecnos.

Secretaría de Relaciones Exteriores. (2013). Reforma energética. Italia: Secretaría de Relaciones exteriores. Disponible en: https://embamex2.sre.gob.mx/italia/images/pdf/ comunicado_037_reforma_energetica.pdf.

De Cabo, M. (2014). Pensamiento crítico, constitucionalismo crítico. Madrid: Trotta.

De Vega García, P. (1998). Mundialización y Derecho Constitucional: la crisis del principio democrático en el constitucionalismo actual. Revista de Estudios Políticos, 100, 13-56.

— (2004). Estudios político-constitucionales. México: Universidad Nacional Autónoma de México.

Ferrara, G. (2012). Regressione constituzionale. Constituzionalismo.it [blog], 18-042012. Disponible en: http://www.costituzionalismo.it/notizie/581/.

Fix-Fierro, H. y Valadés, D. (2017). Constitución Politica de los Estados Unidos Mexicanos. Texto reordenado y consolidado. Anteproyecto. México: Universidad Nacional Autónoma de México.

Fix-Zamudio, H. (2002). Breves reflexiones sobre el concepto y el contenido del derecho procesal constitucional. En E. Ferrer-Mac-Gregor (coord.). Derecho Procesal Constitucional (pp. 165-198). México: Porrúa, Colegio de Secretarios de la Suprema Corte de Justicia de la Nación.

Fritz, K. R. (1985). El ocaso de los mandarines alemanes. Catedráticos, profesores y La comunidad académica alemana, 1890-1933. Barcelona: Ediciones Pomares.

García-Sayán, D. (2005). Una viva interacción: Corte Interamericana y tribunales internos. En La Corte Interamericana de Derechos Humanos. Un cuarto de siglo: 19792004. San José, Costa Rica: Editorial Corte Interamericana de Derechos Humanos. Disponible en: http://www.corteidh.or.cr/docs/libros/cuarto\%20de\%20siglo.pdf.

Gary Jeffrey, J. (2010). Constitutional identity. Cambridge, Massachusetts: Harvard University Press.

González, M. (1992). Las relaciones de la Iglesia y el Estado en México. En E. Andrade (comp.). Estudios jurídicos en torno a la Constitución mexicana de 1917, en su septuagésimo quinto aniversario (pp. 339-354). México: Instituto de Investigaciones Jurídicas.

Hitters, J. C. (2009). Control de constitucionalidad y control de convencionalidad. Comparación. Criterios fijados por la Corte Interamericana de Derechos Humanos. 
Estudios Constitucionales, 7, 109-128. Disponible en: https://doi.org/10.4067/ S0718-52002009000200005.

Jáuregui, G. (1998). Estado, soberanía y constitución: algunos retos del Derecho Constitucional ante el siglo xxi. Revista de Derecho Político, 44, 45-74. Disponible en: http://e-spacio.uned.es/fez/eserv/bibliuned:Derechopolitico-1998-44-E2EDOFBC/PDF.

Jellinek, G. (1991). Reforma y mutación de la constitución. Madrid: Centro de Estudios Políticos y Constitucionales.

Klug, H. (2011). Constitutional identity and change. Tulsa Law Review, 47, 40-49. Disponible en: http://digitalcommons.law.utulsa.edu/cgi/viewcontent.cgi?article=2760\&context=tlr.

López, J. (1993). El sentimiento constitucional (aproximación al estudio del sentir constitucional como modo de integración política) de Pablo Lucas Verdú. Boletín Mexicano de Derecho Comparado, 76, 284-286. Disponible en: http://www.redalyc.org/ articulo.oa? id=42707624.

Lucas Verdú, P. (1985). El sentimiento constitucional (aproximación el estudio del sentir constitucional como modo de integración política). Madrid: Reus.

(2009). Sobre los valores. Teoría y realidad constitucional, 9, 117-132. Disponible en: https://dialnet.unirioja.es/servlet/articulo?codigo=3003932.

Medina, A. (2006). Breves apuntes respecto al principio de la no reelección en México. Letras Jurídicas, Revista Electrónica de Derecho, 3, 1-19.

México. Gobierno de la República. (2013). Reforma político-electoral. México: Gobierno de la República. Disponible en: https:/www.gob.mx/cms/uploads/attachment/ file/3080/EXPLICACION_AMPLIADA_REFORMA_POLITICA_ELECTORAL.pdf.

Meyer Walerstein, E. (1992). Obra política de Luis Cabrera. México: Universidad Nacional Autónoma de México.

Nogueira Alcalá, H. (2006). Los límites del poder constituyente y el control de constitucionalidad de las reformas constitucionales en Chile. Estudios Constitucionales, 2, 435-455. Disponible en: http://www.redalyc.org/pdf/820/82040119.pdf.

Noguera Fernández, A. (2014). Las últimas reformas constitucionales latinoamericanas: hacia una ciudadanía inclusiva. En M. de Peralta Carrasco et al. (coords.). Estudios jurídicos de aproximación del derecho latinoamericano y europeo (pp. 207-212). España: Dykinson.

Núñez Poblete, M. (2008). Introducción al concepto de identidad constitucional y a su función frente al derecho supranacional e internacional de los derechos de la persona. Ius et Praxis, 2, 331-372. Disponible en: http://www.scielo.cl/pdf/iusetp/ v14n2/art10.pdf.

Pampillo Baliño, J. (2014). La integración jurídica y el ius commune americano como proyecto de utopía para la tradición jurídica occidental. Anuario Facultad de Derecho, 7, 93-140. Disponible en: https://dialnet.unirioja.es/servlet/articulo?codigo $=5180651$.

Pisarello, G. (2014). Procesos constituyentes. Caminos para la ruptura democrática. Madrid: Trotta. 
Rabasa, E. O. (2000). Historia de las Constituciones mexicanas. México: Instituto de Investigaciones Jurídicas de la UNAM.

Real Academia Española. (2006). Diccionario de la lengua española. Disponible en: http:// dle.rae.es/?id=VUbdj3r.

Reyes, H. (1967). El liberalismo mexicano. México: Fondo de Cultura Económica.

Sagüiés, P. (2004). Reflexiones sobre la manipulación constitucional. Comunicación del académico correspondiente, en sesión privada de la Academia Nacional de Ciencias Morales y Políticas. Buenos Aires: Centro Interdisciplinario de Derecho Procesal Constitucional. Disponible en: http://www.ancmyp.org.ar/user/files/Reflexion-manipulacion-Sagues.pdf .

- (2010). El control de convencionalidad como instrumento para la elaboración de un ius commune interamericano. En A. V. Bogdandy et al. (coords.). La justicia constitucional y su internacionalización: ¿hacia un ius constitutionale commune en América Latina? (pp. 449-468). México: UNAM-Max Planck Institut. Disponible en: http://biblio.juridicas.unam.mx/libros/6/2895/15.pdf.

Smend, R. (1985). La Constitución y Derecho Constitucional. Madrid: Centro de Estudios Políticos y Constitucionales.

Sunstein, C. (2001). Designing democracy: What constitutions do. New York: Oxford University Press.

Tushnet, M. (2010). How do constitutions constitute constitutional identity? Oxford Journals International of Constitutional Law, 8 (3), 671-676. Disponible en: https:// doi.org/10.1093/icon/moq025.

Universidad Nacional Autónoma de México. (2011). Segunda encuesta nacional de cultura constitucional (Informe de resultados. Instituto Nacional Electoral). México: UNAM.

Vicher, D. (2014). La influencia de la OCDE en la elaboración de la política económica. Análisis, 18, 114-132. Disponible en: http://www.olafinanciera.unam.mx/ new_web/18/pdfs/VicherOlaFinanciera18.pdf. 